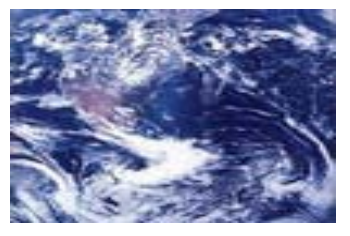

International Review of Research in Open and Distance Learning

ISSN: 1492-3831

Volume 6, Number 1.

March - 2005

\title{
Book Review - Online Education Using Learning Objects
}

Editor: McGreal, R. (2004). Online Education Using Learning Objects. RoutledgeFalmer: London and New York. Hardback. ISBN: 0415335124

Reviewed by: Sanjaya Mishra, Reader in Distance Education, Staff Training and Research Institute of Distance Education, Indira Gandhi National Open University, India

In the context of online education, the use of "learning objects" (LOs) has received much attention in the recent past because of the range of "abilities" that LOs offer the field of teachinglearning. This book is all about creation of LOs, their standardization and contextualization, how LOs are currently used, and the emerging scenario of the semantic Web. McGreal's work complements the book Reusing Online Resources: A sustainable approach to e-learning, edited by Allison Littlejohn (Reviewed by Sanjaya Mishra: http://www.irrodl.org/content/v5.1/mishra_review.html).

Divided into five parts, Online Education Using Learning Objects covers 26 chapters excluding the introduction by the editor, Rory McGreal, who provides an excellent overview of learning objects and the concept of metadata "to help readers to get the most out of the chapters that follow" (p.14). In his overview of the terminologies and metaphors used in describing LOs, McGreal defines LOs "as any reusable digital resource that is encapsulated in a lesson or assemblage of lessons grouped in units, modules, courses and even programmes” (p.13).

Part I, "Learning Objects and Metadata," comprises five chapters presenting the basic concepts and pedagogy behind LOs. In Chapter 1, Stephen Downes - a guru of LOs - details the need for LOs and the importance of sharing them to create advantages through economies of scale. In Chapter 2, Mike Sosteric and Susan Hesemeier, question the heavy dependence on objectoriented programming (OOP), an approach they use to explain LOs in terms of their re-usability. It is from this context that Sosteric and Hesemeier ask several questions to put LO research back on the track of theory development. In Chapter 3, Rob Koper and Rene van Es of the Open University of Netherlands present the framework of the educational modeling language, which has now become part of the IMS Learning Design specifications. In Chapter 4, Norm Friesen, who is engaged in the CanCore initiative, describes three pitfalls: first, the terminology "learning objects" itself, on the one hand, is pedagogical (learning), while the other, it is technological (objects); second, the pedagogical neutrality of the LO standards causes barriers in 
contextualization; and third, the origin of the concept vis-à-vis the American-military industrial context is "antithetical" to education. In Chapter 5, Erik Duval and Wayne Hodgins critically analyze advanced and innovative interpretations of the use of LOs by looking into their taxonomy, components and aggregation related issues.

Part II, “Constructing and Creating Learning Objects” is comprised of six chapters. In Chapter 6, Mohamed Ally recommends adoption of a learner-centred design from the perspective of cognitive psychology, constructivism, and behaviourism in the design of LOs. Ally further identifies three components of LOs and their micro-strategies. In Chapter 7, Downes suggests the use of Rapid Application Design (RAD) methodology and OOP used in software engineering for the construction of LOs. In Chapter 8, Pithamber Polsani, using Peirce's theory of signs, proposes a semiotic model for creating LOs. In Chapter 9, a group of researchers from the Open University of Netherlands (Monique Doorten, Bas Giesbers, Jose Janssen, Jan Daniels, and Rob Koper) describe the process of transforming existing content into re-usable learning objects. In Chapter 10, Peter Sloep describes the need for an educational modeling language because chunking of content and metadata tagging are not satisfactory. In Chapter 11, John Nesbit and Karen Belfer focus on evaluation of learning objects, and review evaluation models applied to educational software and media. Subsequently they propose a convergent participation model of collaborative evaluation of LO.

Part III, "Contextualization and Standardization of Learning Objects," as the title itself suggests, introduces the concept of contextualization and explains standardization issues in LOs for their reuse, in the five chapters that comprise this section. In Chapter 12, Robby Robson emphasizes that the high contextual nature of LOs adds significant cost to reuse and thus little reuse can be seen in the real educational world, even though "reuse" is one of the most important features of LOs. In Chapter 13, Jon Mason outlines the importance of context in learning, and describes the context-driven metadata tags and specifications that would be useful in reuse of LOs. In Chapter 14, researchers from the Lower Saxony Learning laboratory in Germany (Heidrun Allert, Chistoph Richter, Hadhami Dhraif and Wolfgang Nejdl) describe their contextual metadata model for the Open Learning Repository 3 (LOR3). The OLR3 portal is based on a scenario design approach comprised of a domain model, an instructional model, and a structural model that helps learners and teachers to search LOs on the Web and communicate with each other. In Chapter 15, Luis Anido describes reference architecture for offering common e-learning services by Educational Content Providers (ECPs) and Educational Service Providers (ESPs). In Chapter 16, Demetrios Sampson and Pythagoras Karampiperis discuss management of learning object repositories, and describe the functional elements and components of a Learning Object Metadata Management System (LOMMS). The importance of such a system becomes significant while interoperating LOs from one system to other, and while mapping between two different metadata schemas.

Part IV, "Learning Object Profiles, Application and Models," is comprised of five chapters and introduces some well known application profiles and models used in implementation of LOs. In Chapter 17, Norm Friesen, Susan Hesemeier and Anthony Roberts describe CanCore application profile, while Chapter 18 by Griff Richards, Marek Hatala, and the book’s editor, Rory McGreal, 
discuss the Portal for Online Objects in Learning (POOL) project and associated developments. In Chapter 19, Mikael Nilson, Ambjorn Naeve, and Matthias Palmer, describe the Edutella peerto-peer network for exchanging information about LOs and not simply exchanging content. In Chapter 20, Gilbert Paquette, Karin Lundgren-Cayrol, Alexis Miara, and Louis Guerette, present the Explor@2 learning objects manager, which is based on the CanCore metadata schemata. Explore@2 has been designed as a suite useful to learners, content experts, teachers, and managers, and works as a specialized Learning Content Management System (LCMS). In Chapter 21, Neil Kestner describes the use of learning object repository (MERLOT) for developing a professional evaluation model to promote scholarship of teaching in the universities. MERLOT is a unique system that recognizes the work of teachers in developing quality LOs (it is satisfying to know that anonymous reviews by experts are highly rated in promotions and tenure packages).

Part V, "From the Semantic Web to EMP and Instructional Engineering," comprised of five chapters, introduces some complex aspects of LOs and their usage in education. In Chapter 22, for instance, Sean Palmer explores concept of semantic Web and related terminologies such as Resource Description Framework (RDF), XML, and Web Ontology Language (OWL). In Chapter 23, Terry Anderson and Anita Petrinjak describe the educational modeling language developed at the Open University of Netherlands that holds the potential to promote the emergence of educational semantic Web. In Chapter 24, Griff Richards and Marek Hatala describe the problems of interoperability in learning object repositories (LOR), and propose development of easy-to-use tools for "cobbling” together a network of LORs. In Chapter 25, Oscar Lin, describes a knowledge modeling approach to design LOs. In the last Chapter, Gilbert Paquette revisits the educational modeling language from an instructional engineering viewpoint, and concludes by suggesting that instructional design has evolved into instructional engineering integrating automatic instructional design, software engineering, and cognitive sciences.

This is a book to be read in depth and detail. McGreal's book has a lot to offer to both new and expert professionals working in the field of LOs. From conceptual clarifications to recent developments on the topic, this book presents an array of highly authoritative explanations and illustrations on this emerging area of educational technology. Rory McGreal is successful in bringing together the "who's who" in LO development, and knitting together a scholarly publication that can be relied upon as a fully informed source and a "what's happening in LOs" from around the world. Although much research is ongoing in the field of LOs, and clearly there are "miles to go" before we can see easy flow of LOs across institutions and national boundaries. The issue of semantic Web has the potential to make this possible, as this is akin to what I called a "classificatory-based organization of learning objects" in my review of the book by Allison Littlejohn. With the last chapter of this book, I also see the emergence of a new phrase that might herald a new fad in educational technology - Instructional Engineering - leading to emergence of new courses, programmes, and perhaps a whole new discipline.

Anyone who is interested in online learning or working in this area cannot afford to miss reading Rory McGreal's book. And even though you may prefer to be selective in your reading of chapters and sequence, this book is a "must read." 


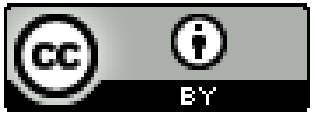

